\title{
Antioxidant status in a group of institutionalised elderly people with chronic obstructive pulmonary disease
}

\author{
Elena Rodríguez-Rodríguez ${ }^{1,2 *}$, Rosa M. Ortega ${ }^{2,3}$, Pedro Andrés ${ }^{1,2}$, Aránzazu Aparicio ${ }^{2,3}$, \\ Liliana G. González-Rodríguez ${ }^{2,4}$, Ana M. López-Sobaler ${ }^{2,3}$, Beatriz Navia ${ }^{2,3}$, José M. Perea ${ }^{2,4}$ and \\ Paula Rodríguez-Rodríguez ${ }^{5}$ \\ ${ }^{1}$ Sección Departamental de Química Analítica, Facultad de Farmacia, Universidad Complutense de Madrid, \\ 28040 Madrid, Spain \\ ${ }^{2}$ UCM Research Group, VALORNUT-920030, Spain \\ ${ }^{3}$ Departamento de Nutrición, Facultad de Farmacia, Universidad Complutense de Madrid, 28040 Madrid, Spain \\ ${ }^{4}$ Departamento de Nutrición Humana y Dietética, Facultad de Ciencias de la Salud, Universidad Alfonso X El Sabio, \\ Villanueva de la Cañada, 28691 Madrid, Spain \\ ${ }^{5}$ Servicio de Neumología, Hospital Fundación Jiménez Díaz, 28040 Madrid, Spain \\ (Submitted 19 October 2015 - Final revision received 5 February 2016 - Accepted 10 February 2016 - First published online 22 March 2016)
}

\section{Abstract}

Chronic obstructive pulmonary disease (COPD) is one of the most important and prevalent diseases suffered by the elderly. Evidence exists that its onset and severity might be conditioned by antioxidant status. The aim of the present study was to investigate the relationship between antioxidant status and COPD in institutionalised elderly people. In all, 183 elderly people aged >65 years (twenty-one had COPD and 160 healthy controls) were studied. The subjects' diets were investigated via the use of precise individual weighing for $7 \mathrm{~d}$. Body weight, height, and biceps and triceps skinfold thickness were measured, and body fat $(\mathrm{kg})$ and BMI $\left(\mathrm{kg} / \mathrm{m}^{2}\right)$ were calculated. Serum retinol, $\alpha$-tocopherol, $\beta$-carotene and vitamin C levels were determined. Subjects with COPD ate less fruits than healthy controls (117 (SD 52) $v$. 192 (SD 161) g/d), their coverage of the recommended intake of vitamin C was smaller (150 (sD 45) v. 191 (sD 88)\%; note that both exceeded $100 \%$ ) and their diets had a lower antioxidant capacity (6558 (sD 2381) v. 9328 (SD 5367) mmol trolox equivalent/d). Those with COPD had lower serum vitamin C and $\alpha$-tocopherol concentrations than healthy controls (32.4 (SD 15.3) $v .41 .5$ (SD 14.8) $\mu \mathrm{mol} / 1$ and 12.1 (SD 3.2) $v$. 13.9 (SD 2.8) $\mu \mathrm{mol} / \mathrm{l}$, respectively). In addition, subjects with $\alpha$-tocopherol $<14 \cdot 1 \mu \mathrm{mol} / 1$ ( 50 th percentile) were at 6.43 times greater risk of having COPD than those subjects with $\geq 14 \cdot 1 \mu \mathrm{mol} / 1$ (OR $6.43 ; 95 \%$ CI $1 \cdot 17,35 \cdot 24 ; P<0.05$ ), taking sex, age, use of tobacco, body fat and vitamin $\mathrm{E}$ intake as covariables. Subjects with COPD had diets of poorer antioxidant quality, especially with respect to vitamins $\mathrm{C}$ and $\mathrm{E}$, compared with healthy controls

Key words: Chronic obstructive pulmonary disease: Antioxidants: Ageing

Chronic obstructive pulmonary disease (COPD) is a chronic, inflammatory ailment of the lungs, in which there is a progressive and irreversible loss of airflow ${ }^{(1,2)}$. At present, there are 210 million people with COPD, and it has been estimated to be the third leading cause of death worldwide by $2030^{(3)}$. Many authors suggest COPD to be very prevalent among the elderly ${ }^{(1,4)}$. In Spain, there are some 21.4 million people between 40 and 80 years of age, among whom 2185764 are affected by the disease ${ }^{(5)}$. Although these figures come from one of the largest studies undertaken in this field, its age limit of 80 years should not go unnoticed.

Among the factors that might contribute towards the development of COPD are genetic background (especially those types leading to a deficiency in $\alpha$-1-antitrypsin), exposure to oxidising agents (e.g. those in atmospheric pollution and tobacco smoke) and reduced antioxidant capacity ${ }^{(6-8)}$. Certainly, people with COPD experience increased oxidative stress, which reduces airflow. This could lead to a greater demand for antioxidant nutrients such as vitamins $\mathrm{C}$ and $\mathrm{E}$ and carotenoids, which might leave COPD patients more vulnerable to deficiencies $^{(9-11)}$. For example, in a group of 218 patients diagnosed with asthma and/or COPD, serum $\beta$-cryptoxanthin, lutein/zeaxanthin and retinol concentrations were found to be significantly and positively associated with the forced expiratory volume in $1 \mathrm{~s}\left(\mathrm{FEV}_{1}\right)$ - the most important measure of airflow.

Abbreviations: BF, body fat; COPD, chronic obstructive pulmonary disease; ORAC, oxygen radical absorbance capacity; RI, recommended intakes; TAC, total antioxidant capacity.

* Corresponding author: E. Rodríguez-Rodríguez, fax +34 91394 17 54, email elerodri@ucm.es; grupo920030@gmail.com 
The antioxidant status of patients with COPD may therefore be important in terms of the progression of the disease ${ }^{(10)}$.

Although COPD is one of the most common diseases affecting the elderly, a few studies on antioxidant status in this population have been performed ${ }^{(10,12)}$. The aim of the present study was, therefore, to determine the antioxidant status of a group of institutionalised elderly people.

\section{Methods \\ Study subjects}

This case-control study included elderly people over 65 years of age, residing in four homes for the elderly in the Region of Madrid, Spain. The health personnel at the different homes selected the subjects after checking their medical records, their cognitive functional and affective capacity scores, and prescribed medication. This study was part of a larger study $^{(13)}$, aimed at selecting groups of subjects with similar nutritional, cognitive and affective characteristics in order to include them in a nutritional intervention trial. The starting number for each group was about fifty subjects. Centres with less than sixty possible participants were excluded.

All subjects were informed of the characteristics of the study, and their signed consent to be included was requested. Those who did not provide signed consent were excluded, as well as those with any condition that might affect the digestion, absorption or utilisation of nutrients (neoplasms, cirrhosis, abnormal liver function, poor intestinal absorption, etc.) and those showing signs of manifest cognitive decline (i.e. with a Lobo \& Ezquerra test score of $\left.<24^{(14)}\right)$. Individuals for whom alcohol made up $>10 \%$ of their daily energy intake were also excluded. A total of 183 elderly people (sixty-three men and 120 women) completed the study.

The present study followed the principles of the Declaration of Helsinki and was approved by the Human Research Review Committee of the Pharmacy Faculty, Complutense University of Madrid. Signed informed consent was obtained from all participants.

\section{Dietary study}

The subjects' consumption of food and intake of nutrients were determined by the 'precise individual weighing' method over a period of 7 consecutive days (including a weekend to take into account any change in the normal daily diet ${ }^{(15)}$. The individual portions consumed at each of the main meals (breakfast, lunch, early evening snack, evening meal) were weighed, as were the amounts left on the plate after eating. The subjects could choose their meals as the homes offered a range of menus. Thus, the foods recorded over this 7-d period likely reflect the normal food choices made by the subjects. All foods consumed outside established mealtimes, as well as outside of the homes, were reported by the subjects themselves.

The dietary data collected were treated using DIAL software $^{(16)}$ in order to determine the amounts of the different food groups consumed, the nutrient and energy intakes, the total antioxidant capacity (TAC) of the diet and the adequacy of the intake of different dietary components, especially vitamins A, C and $\mathrm{E}$, with respect to recommended intakes (RI).

TAC can be determined in different ways including the ferricreducing antioxidant power (FRAP) method, which determines the capacity to reduce a ferric complex ${ }^{(17)}$, the radical trapping antioxidant parameter (TRAP) method, based on the thermal decomposition of azo-hydrosoluble compounds that produce peroxyl radicals ${ }^{(18)}$, the trolox equivalent antioxidant capacity (TEAC) method, which measures the capacity to reduce the ABTS+ (2,2'-azinobis(3-ethylbenzothiazoline-6-suslfonic acid) radical under lipophilic and hydrophilic conditions ${ }^{(19)}$, and the oxygen radical absorbance capacity (ORAC) method, which measures the oxidative degradation of a fluorescent molecule subjected to a flow of peroxyl radicals ${ }^{(20)}$. In the present study, the TAC of the diets was determined using values recorded in the Spanish Food Composition Tables ${ }^{(21)}$, drawn up by collecting values published by different authors. The database used contained 483 measurements made by the FRAP method ( $\mathrm{mmol} / 100 \mathrm{~g}$ ), 140 by the TRAP method (trolox equivalent (TE) mmol/100 g), 158 by the TEAC method (TE mmol/100 g) and 225 by the ORAC method (TE mmol/100 g).

\section{Presence of chronic obstructive pulmonary disease}

The medical histories of the subjects were examined in search of information on/diagnoses of COPD. When this information was insufficient to identify a subject as having this problem, the doctor who attended to the subjects at each home was asked for assistance. COPD was deemed present when, following the inhalation of bronchodilators, the $\mathrm{FEV}_{1} /$ forced vital capacity multiplied by 100 was $<70 \%{ }^{(22,23)}$.

Of the 183 subjects who took part in the present study, twenty-one were deemed to have COPD.

\section{Other covariables}

Information was also collected on risk factors for COPD, such as age (years), smoking habits (non-smoker, ex-smoker, smoker), alcohol consumption and use of multivitamin supplements.

\section{Anthropometric study}

Body weight was determined using a Seca Alpha digital balance (range 0.1-150 kg; accuracy $100 \mathrm{~g}$; Seca Alpha, GmbH \& Co.), with the subjects wearing only underwear and standing on the centre of the horizontal plate. Body weight of subjects who found it difficult to stand was determined using an Alpha 6868 medical balance equipped with a seat (range $1-360 \mathrm{~kg}$ ).

Height was determined using a Harpenden digital stadiometer (range 70-205 cm; accuracy $1 \mathrm{~mm}$; Pfifter). Subjects were measured while standing, holding the back as straight as possible and with the arms parallel to the body, heals together and the head in the Frankfort horizontal plane. This measurement was taken only for those subjects who could maintain a standing position. For subjects with problems of balance or conditions affecting the vertebral column (kyphosis, sclerosis), 
height was estimated from the knee-heel distance using the formula of Chumlea ${ }^{(24)}$ :

$$
\begin{aligned}
& \text { Men : } 64 \cdot 2-(0 \cdot 04 \text { age }(\text { years })) \\
& +(2 \cdot 02 \text { distance knee }- \text { heel }(\mathrm{cm})) \\
& \text { Women : } 89 \cdot 4-(0 \cdot 24 \text { age }(\text { years })) \\
& +(1 \cdot 83 \text { distance knee }- \text { heel }(\mathrm{cm})) .
\end{aligned}
$$

BMI was then calculated from the height and body weight measurements ${ }^{(25)}$ :

$$
\operatorname{BMI}\left(\mathrm{kg} / \mathrm{m}^{2}\right)=\frac{\text { weight }(\mathrm{kg})}{\operatorname{height}^{2}\left(\mathrm{~m}^{2}\right)} \text {. }
$$

Skinfolds (biceps and triceps) were measured using a Holtain skinfold caliper (range 0-40 mm; accuracy 0.1 mm Holtain Ltd), applying a constant pressure of $10 \mathrm{~g} / \mathrm{mm}^{2}$ over the contact surface. Measurements were taken on the non-dominant side of the body. All readings were taken after some $4 \mathrm{~s}$ with the caliper in place to reduce the variation associated with skin compressibility $^{(26)}$. The biceps skinfold thickness was measured over the cubital fossa with the arm relaxed, at the mid-point between the acromion and the olecranon. The triceps skinfold thickness was measured with the arm relaxed, also at the mid-point between the acromion and the olecranon.

The percentage of body fat (BF\%) was calculated using the equation of $\operatorname{Siri}^{(27)}$ :

$$
\mathrm{BF} \%=\left(\frac{495}{D}\right)-450
$$

where $D$ is the density term calculated using the equation of Durnin \& Womersley ${ }^{(28)}$ :

$D=c$

$-(m \times \log$ (sum of the biceps and triceps skinfold thicknesses $))$, in which $c=1.1185$ for men and 1.1226 for women, and $m=0.0683$ for men and 0.0710 for women.

Once BF\% was known, BF mass (kg) was determined using the equation of Méndez \& Lukaski ${ }^{(29)}$ :

$$
\mathrm{BF}(\mathrm{kg})=\frac{(\mathrm{BF} \% \times \text { weight }(\mathrm{kg}))}{100} .
$$

\section{Blood sample collection}

Blood samples were collected by venepuncture between 08.00 and 09.00 hours in the morning after $12 \mathrm{~h}$ of fasting. Adherence to the fasting period was checked by nurses before blood was collected. All sample collections were performed at the respective centres.

\section{Biochemical study}

Retinol and $\alpha$-tocopherol levels were determined together by reversed-phase HPLC following the method of Driskel et al. ${ }^{(30)}$. The mobile phase was a 95:5 mixture of methanol-water, the flow rate was $1.0 \mathrm{ml} / \mathrm{min}$ and the column was a Supelcosil LC-18 model $(4.2 \times 150 \mathrm{~mm} ; 5 \mu \mathrm{m}$ particle size; Sigma-Aldrich Co. LLC). All determinations were made using a Varian 5000 apparatus equipped with a Varian variable wavelength UV detector (Varian BV). Vitamin A detection was performed at $325 \mathrm{~nm}$ and vitamin $\mathrm{E}$ detection at $294 \mathrm{~mm} 3$ min later. Retinyl acetate and tocopheryl acetate were used as internal standards $(\mathrm{CV}=2.4 \%$ for retinol and $2 \cdot 8 \%$ for tocopherol).

$\beta$-Carotene was also determined by reversed-phase HPLC. The target molecule was extracted from $100 \mu \mathrm{l}$ serum samples via the addition of $120 \mu \mathrm{l} n$-hexane plus $100 \mu \mathrm{l}$ of echinenone as an internal standard. The mixture was then centrifuged $(500 \mathrm{~g}$, $5 \mathrm{~min}$ ) and $100 \mu \mathrm{l}$ of the supernatant was extracted. This was then evaporated in a $\mathrm{N}$ atmosphere at $50^{\circ} \mathrm{C}$. The lipid residue was then reconstituted in $100 \mu \mathrm{l}$ of a mobile phase (70\% acetonitrile, $20 \%$ dichloromethane, $10 \%$ methanol). Separation was performed using a Supelcosil LC-18 column $(4.6 \times 250 \mathrm{~nm} ; 5 \mu \mathrm{m}$ particle size) at a flow rate of $1.7 \mathrm{ml} / \mathrm{min}$. Detection was performed using a UV detector at $436 \mathrm{~nm}(\mathrm{CV}=3 \cdot 3 \%)^{(31)}$.

Vitamin $\mathrm{C}$ was determined via ascorbic acid enzymatic oxidation $^{(32)}$ and the formation of quinoxaline to produce a fluorescent compound that was detectable spectrofluorimetrically ${ }^{(33)}$. The method followed was that of Vuilleumier \& $\mathrm{Keck}^{(34)}$ without automation $(\mathrm{CV}=2 \cdot 9 \%)$.

\section{Statistical analysis}

Values were recorded as means and standard deviations or percentages. The dietary data were adjusted by energy intake using the residuals method. Differences between means were examined using the Student's $t$ test or using the Mann-Whitney test when the distribution of the results was not normal. Linear correlation coefficients were determined between some variables. Categorical variables were compared using the $\chi^{2}$ test. Logistic regression analysis was used to examine the risk factors associated with COPD; these results are presented as OR and 95\% CI. Significance was set at $P<0 \cdot 05$. All calculations were performed using RSIGMA BABEL software (Horus Hardware).

\section{Results}

In all, twenty-one (11.5\%) subjects had COPD. A high percentage of the population had an inadequate vitamin $\mathrm{E}$ and $\beta$-carotene status (Table 1 ). The TAC of the diet, as measured by the ORAC method, was positively and significantly associated with the consumption of fruits $(r 0.7357 ; P<0 \cdot 001)$.

Subjects with COPD were more commonly men and smokers, and their diets had a lower TAC compared with control subjects (Table 2). No significant differences were detected in terms of intake of the studied nutrients. However, the RI of vitamin $\mathrm{C}$ was better covered among the control subjects (Table 2). In addition, subjects with a vitamin intake $<150 \%$ of RI were three times more likely of having COPD than those with higher intakes (OR 2.94; 95\% CI 1.11, 7.75; $P<0 \cdot 05$ ). The main source of vitamin C was fruits $(r 0.8091 ; P<0 \cdot 001)$, and consumption of fruits was higher among the control subjects (Table 2). There were no differences between the control and the COPD groups regarding vitamin A intake. However, those with a vitamin A intake $<75 \%$ of the RI were 2.69 times more likely of having COPD than those with higher intakes (OR 2.79; $95 \%$ CI $1.01,7 \cdot 23 ; P<0.05)$. 
Table 1. Characteristics of the study population (Mean values and standard deviations)

\begin{tabular}{|c|c|c|}
\hline & Mean & SD \\
\hline$n$ & \multicolumn{2}{|c|}{183} \\
\hline Age (years) & $82 \cdot 4$ & $7 \cdot 0$ \\
\hline$\%$ COPD & \multicolumn{2}{|c|}{$12 \cdot 7$} \\
\hline Sex (\% men) & \multicolumn{2}{|c|}{34.4} \\
\hline BMI $\left(\mathrm{kg} / \mathrm{m}^{2}\right)$ & $29 \cdot 2$ & $6 \cdot 3$ \\
\hline $\mathrm{BF}(\mathrm{kg})$ & $21 \cdot 3$ & 7.5 \\
\hline Smoking habits (\%) & & \\
\hline Never & \multicolumn{2}{|c|}{$83 \cdot 3$} \\
\hline Ex-smoker & \multicolumn{2}{|c|}{$1 \cdot 3$} \\
\hline Smoker & \multicolumn{2}{|c|}{$15 \cdot 3$} \\
\hline \multicolumn{3}{|l|}{ Use of supplements (\%) } \\
\hline No & & \\
\hline Yes & \multicolumn{2}{|c|}{$59 \cdot 3$} \\
\hline \multicolumn{3}{|l|}{ Dietary data } \\
\hline Energy (kJ) & 7539 & 1004 \\
\hline Energy (kcal) & 1802 & 240 \\
\hline Underestimation (\%) & -0.91 & $16 \cdot 14$ \\
\hline Cereals $(g / d)$ & 163 & 43 \\
\hline Pulses (g/d) & $15 \cdot 9$ & $11 \cdot 8$ \\
\hline Vegetables (g/d) & 263 & 89 \\
\hline Fruits $(g / d)$ & 184 & 155 \\
\hline Dairy products $(\mathrm{g} / \mathrm{d})$ & 406 & 118 \\
\hline Meat $(g / d)$ & $95 \cdot 3$ & $39 \cdot 3$ \\
\hline Fish $(g / d)$ & 41.5 & $21 \cdot 1$ \\
\hline Eggs (g/d) & $18 \cdot 6$ & $12 \cdot 1$ \\
\hline Oils $(g / d)$ & 33.3 & $15 \cdot 2$ \\
\hline Vitamin C (mg/d) & 112 & 48 \\
\hline Coverage of RI (\%) & 187 & 86 \\
\hline Vitamin E (mg/d) & $12 \cdot 2$ & $5 \cdot 7$ \\
\hline Coverage of RI (\%) & 115 & 58 \\
\hline$a$-Tocopherol (mg/d) & 9.90 & $5 \cdot 89$ \\
\hline Vitamin A $(\mu \mathrm{g} / \mathrm{d})$ & 786 & 236 \\
\hline Coverage of RI (\%) & 103 & 36 \\
\hline Retinol $(\mu \mathrm{g} / \mathrm{d})$ & 293 & 68 \\
\hline$\beta$-Carotene $(\mu \mathrm{g} / \mathrm{d})$ & 2550 & 1173 \\
\hline ORAC (mmol TE/d) & 9034 & 5199 \\
\hline FRAP (mmol Fe(II)/d) & 4.01 & 1.75 \\
\hline TRAP (mmol TE/d) & $4 \cdot 13$ & 1.65 \\
\hline TEAC (mmol TE/d) & 3.12 & 1.31 \\
\hline \multicolumn{3}{|l|}{ Biochemical data } \\
\hline Vitamin C $(\mu \mathrm{mol} / \mathrm{l})$ & $40 \cdot 3$ & $14 \cdot 8$ \\
\hline$\%$ Deficiency $(<22.7 \mu \mathrm{mol} / \mathrm{l})$ & \multicolumn{2}{|c|}{11.8} \\
\hline Plasma $\beta$-carotene $(\mu \mathrm{mol} / \mathrm{l})$ & 0.38 & 0.42 \\
\hline \% Deficiency $(<0.186 \mu \mathrm{mol} / \mathrm{l})$ & \multicolumn{2}{|c|}{$40 \cdot 8$} \\
\hline Retinol $(\mu \mathrm{mol} / \mathrm{l})$ & \multirow{2}{*}{\multicolumn{2}{|c|}{4.48}} \\
\hline \% Deficiency $(<1.05 \mu \mathrm{mol} / \mathrm{l})$ & & \\
\hline Vitamin E (a-tocopherol) $(\mu \mathrm{mol} / \mathrm{l})$ & $13 \cdot 7$ & 2.9 \\
\hline \% Deficiency $(<11.6 \mu \mathrm{mol} / \mathrm{l})$ & \multicolumn{2}{|c|}{23.9} \\
\hline \% Low level $(11 \cdot 6-23.2 \mu \mathrm{mol} / \mathrm{l})$ & \multicolumn{2}{|c|}{$76 \cdot 1$} \\
\hline$\%$ Optimum level (>27.9 $\mu \mathrm{mol} / /)$ & \multicolumn{2}{|c|}{0} \\
\hline
\end{tabular}

COPD, chronic obstructive pulmonary disease; $\mathrm{BF}$, body fat; $\mathrm{RI}$, recommended intake ORAC, oxygen radical absorbance capacity; TE, trolox equivalent; FRAP, ferricreducing antioxidant power; TRAP, trapping antioxidant parameter; TEAC, trolox equivalent antioxidant capacity.

Subjects with COPD had lower serum vitamin C and $\alpha$-tocopherol levels than the control subjects, although no significant differences were seen between the two groups regarding the percentage of people with deficient levels (Table 2)

Logistic regression analysis showed that subjects with a serum vitamin $\mathrm{C}$ concentration $<42 \mu \mathrm{mol} / \mathrm{l}$ (i.e. below 50th percentile) were 3.59 times more likely of having COPD than those with concentrations $\geq 42 \mu \mathrm{mol} / \mathrm{l}$ (OR 3.59; 95\% CI 1.13, 11.41; $P<0.05)$. Similarly, subjects with serum $\alpha$-tocopherol
$<14.1 \mu \mathrm{mol} / \mathrm{l}$ (i.e. below 50th percentile) were $4 \cdot 17$ times more likely of having COPD than those with higher levels (OR 4.17; 95\% CI 1.11, 15.69; $P<0.05)$. When taking the covariables sex, age, use of tobacco, $\mathrm{BF}$ and vitamin $\mathrm{C}$ or $\mathrm{E}$ (as required) into account, this relationship was lost for vitamin C (OR 4.31; $95 \%$ CI $0.97,19.30 ; P>0.05)$ but was significant for $\alpha$-tocopherol (OR 6.43; $95 \%$ CI $1 \cdot 17,35 \cdot 24 ; P<0 \cdot 05$ ).

\section{Discussion}

Oxidative stress appears to play an important role in the pathogenesis of COPD. An adequate intake of antioxidant nutrients, and an adequate status of these nutrients, might therefore be beneficial in the maintenance of pulmonary function in patients with this condition ${ }^{(35)}$. A study involving 14120 adults over 17 years of age showed that higher serum concentrations of vitamins $\mathrm{A}, \mathrm{C}, \mathrm{E}$ and $\beta$-cryptoxanthine were independently associated with higher $\mathrm{FEV}_{1}$ scores $^{(9)}$ - a finding in line with the results of the present study.

Although the contribution of vitamin $\mathrm{C}$ intake towards covering its RI was indeed high, over $100 \%$, it was even higher among the control subjects. These results suggest that a coverage $>150 \%$ may offer protection against the appearance of COPD. This agrees with that reported by other authors. For example, Ahmadi et al. ${ }^{(36)}$ and Lin et al. ${ }^{(12)}$ reported smaller intakes of vitamin $\mathrm{C}$ among patients with COPD compared with healthy controls, and the latter authors also reported greater consumption of fruits and vegetables among control subjects. In addition, in a study of 2917 Finnish men who were followed-up for 20 years, it was noticed that for every $100 \mathrm{~g}$ increase in fruit consumption, the risk of developing COPD fell by $24 \%{ }^{(37)}$. This finding also agrees with the present results: greater fruit consumption - the main source of vitamin $\mathrm{C}$ - was seen among the healthy subjects.

As seen at the dietary level, and in agreement with other authors $^{(9,12)}$, higher serum vitamin $\mathrm{C}$ concentrations seemed to offer protection against COPD. When use of tobacco was taken into account as a covariable, this effect was lost. Certainly, it has been reported that, in vitro, the plasma concentration of this vitamin falls significantly in the presence of tobacco smoke as a consequence of lipid peroxidation ${ }^{(38)}$. As the majority of our subjects with COPD were smokers (Table 2), and given that smoking is an important risk factor for low serum vitamin $\mathrm{C}$ concentrations, it would seem reasonable to recommend that the intake of this vitamin/the consumption of fruits be increased and that smoking be ceased.

In addition to having antioxidant activity, vitamin $\mathrm{E}$ exerts anti-inflammatory effects; maintaining an adequate vitamin $\mathrm{E}$ status might therefore be beneficial to patients with $\mathrm{COPD}^{(39)}$. In a recent study involving 38507 women followed-up over 10 years, it was determined that the administration of $400 \mathrm{mg}$ vitamin $\mathrm{E}$ reduced the risk of developing COPD by $10 \%{ }^{(40)}$. In the present study, subjects with COPD not only had less vitamin E intakes compared with healthy controls but also had poorer serum concentrations of the same. Further, serum values below the 50th percentile were associated with four times higher risk of having COPD than higher levels. This relationship held even 
Table 2. Characteristics of the study population depending on chronic obstructive pulmonary disease (COPD) status $\dagger$ (Mean values and standard deviations)

\begin{tabular}{|c|c|c|c|c|}
\hline & \multicolumn{2}{|c|}{ COPD $(n 21)$} & \multicolumn{2}{|c|}{ Normal $(n 160)$} \\
\hline & Mean & SD & Mean & SD \\
\hline Age (years) & $82 \cdot 2$ & $6 \cdot 2$ & $82 \cdot 3$ & $7 \cdot 1$ \\
\hline Sex (\% men) & \multicolumn{2}{|c|}{$57 \cdot 1^{*}$} & \multicolumn{2}{|c|}{$31.9^{*}$} \\
\hline $\mathrm{BMI}\left(\mathrm{kg} / \mathrm{m}^{2}\right)$ & $26 \cdot 5$ & $5 \cdot 7$ & 29.5 & $6 \cdot 3$ \\
\hline $\mathrm{BF}(\mathrm{kg})$ & $17 \cdot 9^{*}$ & $7 \cdot 3$ & $21 \cdot 7^{\star}$ & $7 \cdot 4$ \\
\hline \multicolumn{5}{|l|}{ Smoking habits (\%) } \\
\hline Never & \multicolumn{2}{|c|}{61.9} & \multicolumn{2}{|c|}{38.9} \\
\hline Ex-smoker & \multicolumn{2}{|c|}{0} & \multicolumn{2}{|c|}{1.2} \\
\hline Smoker & \multicolumn{2}{|c|}{$33 \cdot 3^{*}$} & \multicolumn{2}{|c|}{$9 \cdot 9^{*}$} \\
\hline \multicolumn{5}{|l|}{ Consumption of supplements (\%) } \\
\hline No & \multirow{2}{*}{\multicolumn{2}{|c|}{$\begin{array}{l}38 \cdot 1 \\
61.9\end{array}$}} & \multirow{2}{*}{\multicolumn{2}{|c|}{$\begin{array}{l}29.0 \\
40.7\end{array}$}} \\
\hline Yes & & & & \\
\hline \multicolumn{5}{|l|}{ Dietary data } \\
\hline Energy (kJ) & 7339 & 954 & 7565 & 1008 \\
\hline Energy (kcal) & 1754 & 228 & 1808 & 241 \\
\hline Underestimation (\%) & 4.65 & 11.81 & -1.57 & $16 \cdot 49$ \\
\hline Cereals $(\mathrm{g} / \mathrm{d})$ & 150 & 53 & 165 & 42 \\
\hline Pulses (g/d) & $16 \cdot 2$ & $12 \cdot 3$ & $15 \cdot 8$ & 11.8 \\
\hline Vegetables $(\mathrm{g} / \mathrm{d})$ & 280 & 65 & 261 & 92 \\
\hline Fruits $(\mathrm{g} / \mathrm{d})$ & $117^{*}$ & 52 & $192^{*}$ & 161 \\
\hline Dairy products (g/d) & 370 & 95 & 410 & 120 \\
\hline Meat $(g / d)$ & 87.7 & $39 \cdot 1$ & $96 \cdot 2$ & $39 \cdot 3$ \\
\hline Fish $(g / d)$ & 43.8 & $22 \cdot 4$ & $41 \cdot 2$ & $21 \cdot 0$ \\
\hline Eggs $(g / d)$ & $20 \cdot 1$ & $16 \cdot 1$ & $18 \cdot 4$ & 11.6 \\
\hline Oils $(\mathrm{g} / \mathrm{d})$ & 30.8 & $20 \cdot 0$ & 33.6 & 14.6 \\
\hline Vitamin C (mg/d) & $98 \cdot 1$ & $32 \cdot 3$ & $113 \cdot 8$ & $50 \cdot 0$ \\
\hline Coverage of RI (\%) & $150^{\star \star}$ & 45 & $191^{\star \star}$ & 88 \\
\hline Vitamin $E(\mathrm{mg} / \mathrm{d})$ & 14.32 & $5 \cdot 18$ & 11.94 & $5 \cdot 73$ \\
\hline Coverage of RI (\%) & 120 & 52 & 115 & 59 \\
\hline$a$-Tocopherol (mg/d) & 11.36 & 4.65 & 9.73 & 5.62 \\
\hline Vitamin A $(\mu \mathrm{g} / \mathrm{d})$ & 875 & 389 & 776 & 210 \\
\hline Coverage of RI (\%) & 104 & 54 & 10334 & \\
\hline Retinol $(\mu \mathrm{g} / \mathrm{d})$ & 305 & 52 & 291 & 70 \\
\hline$\beta$-Carotene $(\mu \mathrm{g} / \mathrm{d})$ & 2812 & 1415 & 2518 & 1142 \\
\hline ORAC (mmol TE/d) & $6558^{*}$ & 2381 & $9328^{\star}$ & 5367 \\
\hline FRAP (mmol Fe(II)/d) & 3.42 & 0.87 & 4.08 & 1.82 \\
\hline TRAP (mmol TE/d) & 3.86 & 1.41 & $4 \cdot 16$ & 1.67 \\
\hline TEAC (mmol TE/d) & $2 \cdot 81$ & 0.93 & 3.16 & 1.34 \\
\hline \multicolumn{5}{|l|}{ Biochemical data } \\
\hline Vitamin C $(\mu \mathrm{mol} / \mathrm{l})$ & $32 \cdot 4^{*}$ & $15 \cdot 3$ & \multicolumn{2}{|l|}{$41.5^{\star}$} \\
\hline$\%$ Deficiency $(<22.7 \mu \mathrm{mol} / \mathrm{l})$ & \multicolumn{2}{|c|}{$22 \cdot 2$} & & \\
\hline Plasma $\beta$-carotene $(\mu \mathrm{mol} / \mathrm{l})$ & \multirow{2}{*}{\multicolumn{2}{|c|}{$30 \cdot 8$}} & \multirow{2}{*}{\multicolumn{2}{|c|}{41.8}} \\
\hline \% Deficiency $(<0.186 \mu \mathrm{mol} / \mathrm{l})$ & & & & \\
\hline Retinol $(\mu \mathrm{mol} / \mathrm{l})$ & 21.3 & 0.49 & \multirow{2}{*}{\multicolumn{2}{|c|}{2.04}} \\
\hline$\%$ Deficiency $(<1.05 \mu \mathrm{mol} / \mathrm{l})$ & \multicolumn{2}{|c|}{$7 \cdot 1$} & & \\
\hline Vitamin E (a-tocopherol) $(\mu \mathrm{mol} / \mathrm{l})$ & $12 \cdot 1^{*}$ & $3 \cdot 2^{\star}$ & $13 \cdot 9^{\star}$ & $2 \cdot 8$ \\
\hline$\%$ Deficiency $(<11.6 \mu \mathrm{mol} / \mathrm{l})$ & & & & \\
\hline \% Low level $(11.6-23.2 \mu \mathrm{mol} / \mathrm{l})$ & & & & \\
\hline$\%$ Optimum level $(>27.9 \mu \mathrm{mol} / /)$ & & & & \\
\hline
\end{tabular}

BF, body fat; RI, recommended intake; ORAC, oxygen radical absorbance capacity; TE, trolox equivalent; FRAP, ferric-reducing antioxidant power; TRAP, trapping antioxidant parameter; TEAC, trolox equivalent antioxidant capacity.Significant correlations: ${ }^{*} P<0.05 ;{ }^{* *} P<0.01$.

† Student's $t$ test (or the Mann-Whitney test if the distribution of results was not homogeneous) was used to compare variables between groups. The $x^{2}$ test was used to determine the significance of differences between proportions.

when smoking was taken into account as a covariable. These results are consistent with those reported by Ahmadi et al. ${ }^{(36)}$, who reported vitamin $\mathrm{E}$ intake to be lower in patients with COPD than in healthy controls. Similarly, Lin et al. ${ }^{(12)}$ reported serum vitamin $\mathrm{E}$ concentrations to be lower in patients with COPD, and Tug et al. ${ }^{(41)}$ observed lower serum concentrations in twenty-four patients with COPD during times of disease exacerbation than during times of stability.
All the subjects had low serum $\alpha$-tocopherol concentrations (below $23.2 \mu \mathrm{mol} / \mathrm{l}^{(42)}$ ), yet all had intakes of $>100 \%$ of that recommended. Different factors can be related to this fact. First, absorption of vitamin $\mathrm{E}$ could be decreased by the use of cholesterol medication. Therefore, the elderly with high cholesterol and cholesterol medication might suffer from inadequate vitamin $\mathrm{E}$ intake ${ }^{(43)}$. Second, a relationship between increased oxidative stress and the most important age-related 
pathologies (i.e. CVD and neurodegenerative disease, cancer and diabetes) has been largely demonstrated ${ }^{(44)}$, and antioxidant status has been demonstrated to be compromised in people with chronic diseases ${ }^{(45)}$. According to these, although we did not find any relationship between the use of anticholesterolaemic drugs and serum $\alpha$-tocopherol concentrations, we found that elderly people with $\alpha$-tocopherol serum values below the 50th percentile showed higher percentage of anaemia and ischaemia/heart failure than people with values above the 50th percentile $(5.8 \mathrm{v} .0 \% ; P<0.05$ and $49.3 \mathrm{v}$. $29.0 \% ; P<0.05$, respectively). Thus, the condition of these diseases may compromise the status of vitamin $\mathrm{E}$ in elderly people and, although in our study all subjects had intakes above the RI, the current intake could be insufficient to maintain an adequate status of this vitamin. For this reason, the vitamin E RI in elderly people could be insufficient and should be revised. At the moment, it may be a good idea for these subjects to further increase their intake. It should also be remembered that low serum $\alpha$-tocopherol can result in a low retinyl palmitate concentration ${ }^{(46)}$, making the antioxidant status even worse.

Good coverage of vitamin A intake appeared to offer protection against COPD in our subjects. Similar observations have been reported by other authors. For example, Lin et $a l^{(12)}$ reported lower serum retinol and $\beta$-carotene in patients with COPD compared with healthy controls, and Tug et al. ${ }^{(41)}$ indicated serum vitamin A concentrations to be lower during periods of exacerbation of the disease. In the present study, however, no relationship was seen between COPD and serum $\beta$-carotene - a circumstance also reported by Walda et $a l .{ }^{(37)}$ in their large Finnish study.

The TAC (as measured by the ORAC method - the method of choice according to Awika et $a l^{(47)}$ ) of the diets of the present subjects with COPD was not as great as that of the healthy subjects. Although the literature contains no other reports relating dietary TAC to COPD, some authors report the antioxidant capacity of patients with COPD to be lower. For example, the plasma antioxidant capacity of the eighty patients with COPD, as determined by the FRAP method, was lower than that of the twenty healthy controls $(0.936 v .1 .110 \mathrm{mmol}$ $\left.\mathrm{Fe}^{2+} / \mathrm{l}\right)^{(48)}$. It was also found to be lower, as determined by the TEAC method, in ninety-five patients with COPD compared with thirty-seven healthy controls $(0.81 \quad v .1 .31 \mathrm{mmol} / \mathrm{l})^{(49)}$. As the antioxidant capacities of the plasma and diet are related ${ }^{(50)}$, the results of the present study, and of others studies, suggest that patients with COPD should follow diets rich in components with antioxidant power, especially fruits (note above the significant relationship between fruit intake and the present ORAC results).

Finally, fruit consumption of healthy controls was higher than that of subjects with COPD, which could also be related to a higher intake of phytochemicals such as catechin and flavonoids from this food group. Moreover, in a study carried out in 13651 adults from three Dutch cities, consumption of solid fruits was inversely associated with the prevalence of one or more COPD symptoms (cough, phlegm and breathlessness). Indeed, catechin intake was independently associated with all three COPD symptoms. Nevertheless, flavonol and flavone intakes were independently associated with chronic cough only ${ }^{(51)}$.
Intake of phytochemicals was not assessed in the present study because of the lack of available data in the Spanish food composition database used. As the present study is a casecontrol study, it suffers the limitation in that it cannot identify causal relationships. Moreover, the statistical power of the study was low to detect associations for different exposure factors including the deficiency of vitamin $\mathrm{C}(37.4 \%)$, deficiency of $\beta$-carotene $(14.7 \%)$, deficiency of vitamin A (13\%) and deficiency of vitamin E (28.1\%) owing to the small sample size. Therefore, these results should be interpreted with caution.

In conclusion, the present subjects with COPD had a poorer antioxidant status (especially in terms of vitamins $\mathrm{C}$ and $\mathrm{E}$ ) than the healthy controls, especially those who smoked. It would therefore seem recommendable that the intake of these nutrients, especially via fruit consumption, be increased in such patients.

\section{Acknowledgements}

This work was financed by Unilever Netherlands via the Universidad-Empresa project 138/2000 and the 'Creation and Consolidation Program for Research Groups' at the 'Complutense University of Madrid' (ref no. GR3/14).

R. M. O., A. M. L.-S., E. R.-R. and A. A. contributed to the study design, and E. R.-R., A. A., B. N., J. M. P., L. G. G.-R. and P. R.-R. performed the data collection. R. M. O., A. M. L.-S., E. R.-R., A. A. and P. A. were involved in data analysis and the interpretation of the results. R. M. O., A. A., P. A. and P. R.-R. contributed to the writing of the manuscript.

None of the authors has any conflicts of interest to declare.

\section{References}

1. Martínez N (2013) Guía GesEPOC y pacientes ancianos (Spanish COPD guide and elderly patients). Arch Bronconeumol 49, 367-368.

2. Miravitllesa M, Soler-Cataluñab JJ, Callec M, et al. (2014) Guía española de la EPOC (GesEPOC). Actualización 2014 (Spanish COPD guide (GesEPOC). Update 2014). Arch Bronconeumol 50, Suppl. 1, 1-16.

3. World Health Organization (2016) Burden of COPD. http:// www.who.int/respiratory/copd/en/ (accessed January 2016).

4. Kobayashi S, Yanai M, Hanagama M, et al. (2014) The burden of chronic obstructive pulmonary disease in the elderly population. Respir Investig 52, 296-301.

5. Miravitlles M, Soriano JB, Garcia-Rio F, et al. (2009) Prevalence of COPD in Spain: impact of undiagnosed COPD on quality of life and daily life activities. Thorax 64, 863-868.

6. MacNee W (2005) Pulmonary and systemic oxidant/ antioxidant imbalance in chronic obstructive pulmonary disease. Proc Am Thorac Soc 2, 50-60.

7. Guenegou A, Boczkowski J, Aubier M, et al. (2008) Interaction between a heme oxygenase-1 gene promoter polymorphism and serum beta-carotene levels on 8-year lung function decline in a general population: the European Community Respiratory Health Survey (France). Am J Epidemiol 167, 139-144.

8. Siedlinski M, Postma DS, van Diemen CC, et al. (2008) Lung function loss, smoking, vitamin $\mathrm{C}$ intake, and polymorphisms of the glutamate-cysteine ligase genes. Am J Respir Crit Care Med 178, 13-19.

9. McKeever TM, Lewis SA, Smit HA, et al. (2008) A multivariate analysis of serum nutrient levels and lung function. Respir Res 9, 67. 
10. Ochs-Balcom HM, Grant BJ, Muti P, et al. (2006) Antioxidants, oxidative stress, and pulmonary function in individuals diagnosed with asthma or COPD. Eur J Clin Nutr 60, 991-999.

11. McKeever TM, Scrivener S, Broadfield E, et al. (2002) Prospective study of diet and decline in lung function in a general population. Am J Respir Crit Care Med 165, 12991303.

12. Lin YC, Wu TC, Chen PY, et al. (2010) Comparison of plasma and intake levels of antioxidant nutrients in patients with chronic obstructive pulmonary disease and healthy people in Taiwan: a case-control study. Asia Pac J Clin Nutr 19, 393-401.

13. Bermejo LM, Aparicio A, Rodríguez-Rodríguez E, et al. (2009) Dietary strategies for improving folate status in institutionalized elderly persons. Br J Nutr 101, 1611-1615.

14. Lobo A \& Ezquerra J (1979) El Mini-Mental cognoscitivo: un test sencillo y práctico para detectar alteraciones intelectivas en pacientes médicos (The Cognitive Mini-Mental: a simple and practical test to detect cognitive impairment in medical patients). Actas Luso Esp Neurol Psyquiatr 3, 149-153.

15. Maisey S, Loughridge J, Southon S, et al. (1995) Variation in food group and nutrient intake with day of the week in an elderly population. BrJ Nutr 73, 359-373.

16. Ortega RM, López-Sobaler AM, Andrés P, et al. (2013) DIAL software for assessing diets and food calculations (for Windows, version 3.0.0.5), Department of Nutrition (UCM) \& Alceingeniería, S.A. Madrid. http://www. alceingenieria.net/nutricion.htm (accessed October 2014).

17. Benzie IF \& Strain JJ (1996) The ferric reducing ability of plasma (FRAP) as a measure of 'antioxidant power': the FRAP assay. Anal Biochem 239, 70-76.

18. Ghiselli A, Serafini M, Maiani G, et al. (1995) A fluorescence based method for measuring total plasma antioxidant capability. Free Radic Biol Med 18, 29-36.

19. Rice-Evans C \& Miller NJ (1994) Total antioxidant status in plasma and body fluids. Methods Enzymol 234, 279-293.

20. Prior RL, Hoang H, Gu L, et al. (2003) Assays for hydrophilic and lipophilic antioxidant capacity (oxygen radical absorbance capacity (ORAC(FL)) ) of plasma and other biological and food samples. J Agric Food Chem $\mathbf{5 1}$, 3273-3279.

21. Ortega RM, López-Sobaler AM, Requejo AM, et al. (2010) La Composición De Los Alimentos. Herramienta Básica Para La Valoración Nutricional (Food Composition. A Basic Tool for Assessing Nutritional Status). Madrid: Editorial Complutense.

22. Pauwels RA, Buist AS, Calverley PM, et al. (2001) Global strategy for the diagnosis, management, and prevention of chronic obstructive pulmonary disease. NHLBI/WHO Global Initiative for Chronic Obstructive Lung Disease (GOLD) Workshop summary. Am J Respir Crit Care Med 163, 1256-1276.

23. Rabe KF, Hurd S, Anzueto A, et al. (2007) Global initiative for chronic obstructive pulmonary disease. Global strategy for the diagnosis, management, and prevention of chronic obstructive pulmonary disease: GOLD executive summary. Am J Respir Crit Care Med 176, 532-555.

24. Chumlea CW (1985) Estimating stature from knee height for persons 60 to 90 years of age. J Am Geriatr Soc 33, 116-120.

25. Durnin JVGA \& Fidanza F (1985) Evaluation of nutritional status. Bibl Nutr Dieta 35, 20-30.

26. Becque MD, Katch VL \& Moffatt RJ (1986) Time course of skin-plus-fat compression in males and females. Hum Biol $\mathbf{5 8}$, $33-42$.
27. Siri WE (1956) The gross composition of the body. Adv Biol Med Phys 4, 239-280.

28. Durnin JVGA \& Womersley J (1974) Body fat assessed from total body density and its estimation from skinfold thickness: measurements on 481 men and women aged from 16 to 72 years. Br J Nutr 32, 77-97.

29. Méndez J \& Lukaski HC (1981) Variability of body density in ambulatory subjects measured at different days. Am J Clin Nutr 34, 78-81.

30. Driskel WJ, Neese JW, Bryant CC, et al. (1982) Measurement of vitamin $\mathrm{A}$ and vitamin $\mathrm{E}$ in human serum by high performance liquid chromatography. J Chromatogr 231, 439-444.

31. Bieri JG, Brown ED \& Smith JC (1988) Determination of individual carotenoids in human plasma by high performance liquid chromatography. J Liq Chromatogr 8, 473-484.

32. Beutler HO \& Beinstingl G (1980) Bestimmung von L-Ascorbinsäure in Lebensmitteln (Determination of L-ascorbic acid in food). Dtsch Lebensmitt Rundsch 76, 69-75.

33. Speek AJ, Schrijver J \& Schreus WH (1984) Fluorometric determination of total vitamin $\mathrm{C}$ in whole blood by high-performance liquid chromatography with pre-column derivatization. J Chromatogr 305, 53-60.

34. Vuilleumier JP \& Keck E (1989) Fluorometric assay of vitamin $\mathrm{C}$ in biological materials using a centrifugal analyser with fluorescence attachment. J Micronutr Anal 5, $25-34$.

35. Deslee G1, Woods JC, Moore C, et al. (2009) Oxidative damage to nucleic acids in severe emphysema. Chest $\mathbf{1 3 5}$, 965-974.

36. Ahmadi A, Haghighat N, Hakimrabet M, et al. (2012) Nutritional evaluation in chronic obstructive pulmonary disease patients. Pak J Biol Sci 15, 501-505.

37. Walda IC, Tabak C, Smit HA, et al. (2002) Diet and 20-year chronic obstructive pulmonary disease mortality in middleaged men from three European countries. Eur J Clin Nutr 56, 638-643.

38. Cross CE, O'Neill CA, Reznick AZ, et al. (1993) Cigarette smoke oxidation of human plasma constituents. Ann $N Y$ Acad Sci 686, 72-89.

39. Reiter E, Jiang Q \& Christen S (2007) Anti-inflammatory properties of alpha- and gamma-tocopherol. Mol Aspects Med 28, 668-691.

40. Agler AH, Kurth T, Gaziano JM, et al. (2011) Randomised vitamin E supplementation and risk of chronic lung disease in the Women's Health Study. Thorax 66 , 320-325.

41. Tug T, Karatas F \& Terzi SM (2004) Antioxidant vitamins (A, C and E) and malondialdehyde levels in acute exacerbation and stable periods of patients with chronic obstructive pulmonary disease. Clin Invest Med 27, 123-128.

42. Gámez C, Artacho R, Ruiz-López MD, et al. (1996) Nutritional status of vitamin A and $\mathrm{E}$ in institutionalized elderly people in Granada (Spain). J Nutr Sci Vitaminol (Tokyo) $\mathbf{4 2 ,}$ $397-405$.

43. Herrmann W. \& Obeid R (2011) Vitamins in the Prevention of Human Diseases. Berlin/New York: Walter de Gruyter GmbH \& Co.

44. Dato S, Crocco P, D'Aquila P, et al. (2013) Exploring the role of genetic variability and lifestyle in oxidative stress response for healthy aging and longevity. Int J Mol Sci $\mathbf{1 4}$, 16443-16472.

45. Wang Y, Chun OK \& Song WO (2013) Plasma and dietary antioxidant status as cardiovascular disease risk factors: a review of human studies. Nutrients 5, 2969-3004. 
46. Schäffer MW, Roy SS, Mukherjee S, et al. (2013) Vitamin A, vitamin $\mathrm{E}$, lutein and $\beta$-carotene in lung tissues from subjects with chronic obstructive pulmonary disease and emphysema. Open J Res Dis 3, 44-51.

47. Awika JM, Rooney LW, Wu X, et al. (2003) Screening methods to measure antioxidant activity of sorghum (Sorghum bicolor) and sorghum products. I Agric Food Chem 51, 6657-6662.

48. Emin S, Yordanova K, Dimov D, et al. (2010) Total antioxidant capacity of plasma determined as ferrous reducing ability of plasma in patients with COPD. Trakia J Sci $\mathbf{8}$, 205-213.
49. Rahman I, Swarska E, Henry M, et al. (2000) Is there any relationship between plasma antioxidant capacity and lung function in smokers and in patients with chronic obstructive pulmonary disease? Thorax 55, 189-193.

50. Wang Y, Yang M, Lee SG, et al. (2012) Dietary total antioxidant capacity is associated with diet and plasma antioxidant status in healthy young adults. I Acad Nutr Diet $\mathbf{1 1 2}$, $1626-1635$.

51. Tabak C, Arts IC, Smit HA, et al. (2001) Chronic obstructive pulmonary disease and intake of catechins, flavonols, and flavones: the MORGEN Study. Am J Respir Crit Care Med 164, 61-64. 